\title{
The temporal distribution of autobiographical memory: changes in reliving and vividness over the life span do not explain the reminiscence bump
}

\author{
Steve M. J. Janssen • David C. Rubin • \\ Peggy L. St. Jacques \\ Published online: 6 November 2010 \\ (C) The Author(s) 2010. This article is published with open access at Springerlink.com
}

\begin{abstract}
When autobiographical memories are elicited with word cues, personal events from middle childhood to early adulthood are overrepresented compared to events from other periods. It is, however, unclear whether these memories are also associated with greater recollection. In this online study, we examined whether autobiographical memories from adolescence and early adulthood are recollected more than memories from other lifetime periods. Participants rated personal events that were elicited
\end{abstract}

Steve M. J. Janssen is now at the Department of Psychology of Hokkaido University and Peggy L. St. Jacques is now at the Department of Psychology of Harvard University.

This study was supported by a Rubicon grant from the Netherlands Organization for Scientific Research (NWO) to SJ (Grant number: 446-06-031). We would like to thank Jaap Murre and Martijn Meeter, the founders of the website on which the study was conducted, and James Nairne, David Pillemer, Christopher Burt and one anonymous reviewer for their comments on the paper.

S. M. J. Janssen • D. C. Rubin · P. L. St. Jacques

Department of Psychology and Neuroscience, Duke University,

Durham, NC, USA

\section{S. M. J. Janssen}

Department of Psychology, University of Amsterdam,

Amsterdam, The Netherlands

\section{P. L. St. Jacques}

Center for Cognitive Neuroscience, Duke University,

Durham, NC, USA

S. M. J. Janssen $(\bowtie)$

Department of Psychology, Hokkaido University,

Kita-10, Nishi-7,

Kita-ku, Sapporo 060-0810, Japan

e-mail: janssen@let.hokudai.ac.jp

D. C. Rubin

Center on Autobiographical Memory Research, Aarhus University,

Aarhus, Denmark with cue words on reliving or vividness. Consistent with previous studies, most memories came from the period in which the participants were between 6 and 20 years old. The memories from this period were not relived more or recalled more vividly than memories from other lifetime periods, suggesting that they do not involve more recollection. Recent events had higher levels of reliving and vividness than remote events, and older adults reported a stronger recollective experience than younger adults.

Keywords Recollection · Vividness · Autobiographical memory $\cdot$ Reminiscence bump $\cdot$ Aging

One of the most consistent effects observed in autobiographical memory is the reminiscence bump. While people have hardly any memories for events from the first few years of life (i.e., childhood amnesia) and many memories from the most recent years of their lives as expected from normal forgetting, they also tend to recall more personal events from the reminiscence bump, which is the period between the ages of 10 and 30 years, than from adjacent lifetime periods (Rubin, Rahhal, \& Poon, 1998; Rubin, Wetzler, \& Nebes, 1986; Rybash, 1999).

The reminiscence bump is found in studies that have looked at the most important events of people's lives as well as in studies that have looked at memories that had been sampled with the help of cue words. The particular location of the peak of the reminiscence bump differs depending on how the personal events are elicited. The peak in the distribution of the most important events is located in the third decade of people's lives, whereas in the distribution of word-cued memories it is located in the second decade (Rubin \& Schulkind, 1997). The reminiscence bump has also been observed across a variety of studies including favorite books, 
records and movies (e.g., Holbrook \& Schindler, 1989, 1996; Janssen, Chessa, \& Murre, 2007; Larsen, 1996; Schulkind, Hennis, \& Rubin, 1999; Sehulster, 1996; Smith, 1994) and memory for public events (e.g., Holmes \& Conway, 1999; Howes \& Katz, 1992; Janssen, Murre, \& Meeter, 2008, Rubin et al., 1998; Schuman, Belli, \& Bischoping, 1997). Despite the consistency of the reminiscence bump, however, none of the proposed mechanisms can successfully explain its presence across studies.

Three accounts have been proposed to explain the reminiscence bump, but these accounts are not mutually exclusive (Rubin et al., 1998). First, the cognitive account (Pillemer, 2001; Robinson, 1992) assumes that adolescence consists of many first-time experiences, such as the first day at high school or the first driving lesson, and that these novel events are used later in life as exemplars when people experience similar events. Second, the identity-formation or life-narrative account (Conway, 2005; Conway \& PleydellPearce, 2000; Fitzgerald, 1988, 1996; Rathbone, Moulin, \& Conway, 2008) argues that many self-defining moments, which are vivid and emotional memories of personal events that have a large impact on the identity of a person (Conway, Singer, \& Tagini, 2004), come from adolescence and early adulthood. Third, the life-scripts account hypothesizes that people recall prototypical life events when they are asked to name the most important events of their lives (Berntsen \& Rubin, 2002, 2004; Bohn, in press; Janssen \& Rubin, in press; Rubin \& Berntsen, 2003; Rubin, Berntsen, \& Hutson, 2009; Thomsen \& Berntsen, 2008). These transitional events are mostly positive, although they can sometimes be negative. The positive events tend to occur in early adulthood, while the negative events can happen at any point in people's lives.

Although these three accounts can account for the reminiscence bump in the distribution of the most important life events, they cannot easily explain the increase in the number of memories from adolescence elicited by word cues (Conway \& Haque, 1999; Janssen \& Murre, 2008; Maki \& Naka, 2006; Rubin \& Schulkind, 1997). For example, the reminiscence bump that results from word cues consists not only of more novel, emotional and important events, but also of more regular, unemotional and unimportant events. That is, for word cues, there is the same proportion of novel, emotional, and important memories in the bump as in surrounding periods, suggesting that word-cued memories of all kinds are more easily accessible from the bump period. In contrast, if one cues participants by asking specifically for important or emotionally positive events one produces a bump. Thus, even if word-cued memories from the bump are not more important or emotional, the most easily accessible important and emotionally positive memories are from the reminiscence bump (Berntsen \& Rubin, 2004; Rubin \& Schulkind, 1997). The type of cuing affects the properties of the retrieved memories from the bump.
An important property of autobiographical and episodic memory is that it allows us to subjectively recollect the personal past, which refers to the ability to mentally time travel to alternative temporal locations (Tulving, 2002). Although autobiographical memory is generally associated with episodic memory (Squire, Knowlton, \& Musen, 1993), not all autobiographical memories of events are necessarily episodic. For example, one might recall a personal event without having the experience of traveling mentally back in time and reliving the event (Brewer, 1986).

One frequently used method to distinguish the subjective recollection associated with memory retrieval is the remember/know task (e.g., Dewhurst \& Conway, 1994; Gardiner, 1988; Gardiner \& Java, 1990, 1991; Gardiner \& Parkin, 1990; Rajaram, 1993; Tulving, 1985). For example, Rybash and Monaghan (1999) used these judgments to examine the effect of the age at the time of the event. They presented forty older adults with eighteen cue words and asked them to describe for each word a specific event from their lives. The participants subsequently dated these personal events and indicated whether they remembered or knew the event. Rybash and Monaghan found that the temporal distributions of the remembered and known events consisted both of recency effects and reminiscence bumps. The reminiscence bumps were located in the period in which the participants were between 6 and 15 years old.

Although several researchers have insisted that remember/know judgments do not reflect confidence ratings for laboratory tasks (e.g., Gardiner \& Java, 1990; Rajaram, 1993), for autobiographical memories, they seem to be more closely related to the belief in the accuracy of the memory rather than to the recollective experience (Rubin, Schrauf, \& Greenberg, 2003; Rubin \& Siegler, 2004). A better measure of subjective recollection might therefore be to ask participants directly if and how strongly they relive personal events when they think about them. The property of reliving is also closely linked to vividness, which refers to the strength of visual imagery during retrieval. For example, Rubin et al. (2003) found that highly relived memories had almost always strong visual images. Moreover, reliving ratings are correlated with neural activity in the visual cortex (Daselaar, Rice, Greenberg, Cabeza, LaBar, \& Rubin, 2008).

If personal events that occurred during adolescence and early adulthood are indeed more episodic, then one should find higher values for reliving and vividness for the events that have occurred in those lifetime periods. The goal of the present study was to examine the recollective experience, as measured by reliving and vividness ratings, across the life span of autobiographical memories elicited with cue words. Recollection may depend on three temporal factors: the participant's age at the event, the age of the event, and the age of the participant at the test. The focus of the current 
study, therefore, is to examine whether autobiographical memories from the reminiscence bump have stronger recollective experiences than memories from other lifetime periods, whether recent memories are associated with stronger recollective experiences than remote memories, and whether younger participants have stronger recollective experiences than older participants.

\section{Age at the event}

What makes memories formed in adolescence and early adulthood so special then? Several studies have suggested that the memory system performs optimally in adolescence and early adulthood (e.g., Cerella \& Hale, 1994; Li, Lindenberger, Hommel, Ascherleben, Prinz, \& Baltes, 2004; Salthouse, 2004; also see Rubin et al., 1998, pp. 15-16). One alternative could be that memories from adolescence and early adulthood are encoded better, making them more resilient to changes over time in the recollective experience and thus more likely to be recalled.

\section{Age of the event}

Rybash and Monaghan (1999) examined the age at the event. One can also investigate the age of the event. Cermak (1984) argued that recent personal events are more likely to be episodic and associated with recollection, while most remote memories are semantic. According to some theories (e.g., Schooler, Shiffrin, \& Raaijmakers, 2001) episodic memories lose their contextual information over time and become semantic memories. Following this line of thought, one should find higher values for reliving and vividness for recent than for remote personal events. In addition, many theorists assume that episodic memories are progressively modified in neocortical regions until they are independent of the hippocampal complex (e.g., Alvarez \& Squire, 1994; Meeter \& Murre, 2004; Murre, 1996, 1997; but see, Rosenbaum, Winocur, \& Moscovitch, 2001).

\section{Age of the participant}

Young and older adults may differ in the recollective experience associated with autobiographical memory retrieval. Mäntylä (1993) asked young (20-33 yrs) and older adults (65-78 yrs) to make remember/know judgments about words that they had previously learned. The older adults recalled fewer words than the young adults, but this difference was caused by responses that had been given remember judgments. Young adults gave more remember responses than older adults, but an equal amount of know responses. These results are in line with other studies, in which older adults tend to perform worse than younger adults on episodic memory tests, while they often perform at the same level on semantic memory tests (e.g., Craik \& Jennings, 1992; Park, 2000). The recollective experience might also decline with age, because older adults tend to recall less detailed autobiographical memories (Levine, Svoboda, Hay, Winocur, \& Moscovitch, 2002; Piolino, Desgranges, Benali, \& Eustache, 2002; Piolino, Desgranges, Clarys, GuilleryGirard, Taconnat, \& Isingrini, 2006; St. Jacques \& Levine, 2007). On the basis of these results, one would expect that younger participants give higher ratings of reliving and vividness than older participants.

In contrast to these expectations, two studies of the phenomenological properties of autobiographical memory have found the opposite effect. Rubin and Schulkind (1997) found that older adults, who were 70 or 73 years old, reported higher ratings of vividness for important as well as word-cued memories compared to young adults, who were 20 or 35 years old. This finding was confirmed by Rubin and Berntsen, (2009) who had a sample of nearly 2,000 Danes, ranging in age from 15 to over 90 , recall an important event from last week or from their confirmation day, which occurred when they were about 14 years old, and rate the memory on 11 properties. For the recent event, the correlation between the age of the participant and the ratings were positive and significant (i.e., $r>.06$ ) for all but one rating, with reliving and vividness having correlations of .19 and .14, respectively. For the remote event, only four properties had significant correlations, with reliving and vividness having correlations of .09 and .04 , respectively. Thus, ratings of recent important autobiographical memories may be judged higher by older adults and at least some ratings of word-cued and older important memories might be too. Here, word-cued memories are tested and analyzed with three temporal measures; age at the event, age of the event, and age of the participant.

\section{Internet research}

The present study was conducted on the Internet, which enabled us to collect results from a diverse and large participant population (Gosling, Vazire, Srivastava, \& John, 2004; Reips, 2000, 2002; Schmidt, 1997). The diversity of the population allowed us to look at the effect of the age of the participants at the test on a continuous scale, since we were also able to collect the results of middle-aged adults, who are often overlooked in these studies. The size of the population gave us the opportunity to analyze the results in smaller age bins. Past studies, which used age bins of ten years to display the results, only found reminiscence bumps in the results of participants who were 40 years or older. 
This may be caused by using age bins of ten years. People recall few events from the first decade (child amnesia) and many events from the second decade (reminiscence bump). They also recall many events from the last decade (recency effect). To distinguish the reminiscence bump from a constantly increasing function, one needs at least one data point (between the reminiscence bump and the recency effect) that has fewer memories (third decade). By having more participants, one can use smaller age bins and, possibly, identify the reminiscence bump in the results of participants younger than 40 years (Janssen, Chessa, \& Murre, 2005).

Besides these advantages, there are also limitations to psychological research on the Internet (Gosling et al., 2004; Reips, 2000, 2002; Schmidt, 1997), such as multiple submissions, self-selection bias, absence of physical experimenters, technical variance, and dropout rate. However, one can attenuate the effects of limitations through careful study design, as was implemented in the present study. For example, the influence of multiple submissions can be minimized by supplying passwords and allowing participants to take the test more than once, and double entries can then later be filtered out. Self-selection can be controlled by the multiple site entry technique and by extensive pre-testing. The website on which the test was presented was promoted through other websites, search engines, traditional media (magazines, newspapers, etc.), and word of mouth. The third possible problem of Internet-based research is the absence of a physical experimenter, which could lead to problems during the experiment if the instructions are unclear. Pre-testing the experiment in a usability test and providing the possibility for feedback helps to improve the clarity of the instructions. Another potential problem concerning webbased research is the variance between computers, browsers, and networks, which could lead to reliability problems. Between-participants designs involving pretesting and random distribution of participants to experimental conditions reduce these problems. The use of within-participant designs would eliminate these problems entirely. The dropout rate can be reduced by giving information about the duration of the experiment, feedback about progress during the study, and immediate feedback about performance.

\section{Method}

\section{Participants}

The study, which was called the Galton-Crovitz test, was presented on the website of the University of Amsterdam. Participants who had taken other tests on the website, such as the Daily News Memory Test (Meeter, Murre, \& Janssen, 2005; Meeter, Ochtman, Janssen, \& Murre, 2010) or the Diary Study (Kristo, Janssen, \& Murre, 2009), were invited by e-mail to take part in the study. Other participants had been invited by relatives, friends, or colleagues, who had sent them a standardized e-mail at the end of the study. Additional participants obtained the address of the website from search engines or other websites, newspapers and magazines.

In total 2341 Dutch participants between the ages of 16 and $75(M=47.77, S D=14.31)$ completed the study. The group consisted of 739 men and 1602 women, and more than half of the participants had a university or an equivalent degree $(56.4 \%)$. The participants were divided into twelve age groups of each five years. The number of participants per age group is given in Table 1 . The older age groups consisted of relatively more men $(F(11,2329)=$ $6.30, M S E=0.21, p<.001)$ and of relatively more participants with lower educational attainment $(F(11,2329)=$ 12.63, $M S E=4.14, p<001)$.

\section{Materials and procedure}

The Galton-Crovitz cuing technique (Crovitz \& Schiffman, 1974; Galton, 1879; Robinson, 1976, 1986) was used to elicit autobiographical memories. Sixty-four cue words were selected from Paivio, Yuille, and Madigan, (1968) with values of 6.00 or higher for imagery, concreteness and meaningfulness. The cue words were translated from English to Dutch. The words and their translations are given in the Appendix of Janssen, Chessa and Murre, (2006).

Each participant received a random selection of ten words, which were presented sequentially, and was asked to describe the personal event that first came to mind by writing a short description about the event. The events did not have to be important, but they had to be specific. The
Table 1 Number of participants per age group

\begin{tabular}{llllll}
\hline Age Group & N & Age Group & N & Age Group & N \\
\hline $16-20$ & 116 & $36-40$ & 158 & $56-60$ & 293 \\
$21-25$ & 132 & $41-45$ & 230 & $61-65$ & 248 \\
$26-30$ & 135 & $46-50$ & 314 & $66-70$ & 116 \\
$31-35$ & 144 & $51-55$ & 383 & $71-75$ & 72 \\
Young Adults & 527 & Middle-aged Adults & 1085 & Older Adults & 729 \\
\hline
\end{tabular}


participants were told that "Spring" would be an incorrect response to the cue word "Blossom", but a description of an event that had occurred on a spring day would be correct. After each cue word, participants answered an additional question about when a news event had occurred. The data from these public events was not the focus of the present study and will therefore not be analyzed in the results.

When the participants had given ten descriptions for the personal events and had dated ten news events, they were provided with their descriptions and asked to date each personal event. They could indicate the date on which the event had occurred (e.g., 'July, 2005') or they could indicate how long ago the event had occurred (e.g., ' 5 years ago'). When they wanted to indicate the date, they could select only the year in which the event had happened from a drop-down menu, they could select the month and year, or they could select the exact date (i.e., day of the month, month, and year). When they wanted to indicate how long ago the event had happened, they selected the number of time units and the corresponding time unit (i.e., days, weeks, months, or years) from drop-down menus. The order in which the two answering formats were presented on the computer screen was counterbalanced.

After participants had dated each personal event, half of the participants indicated how strongly they relived the event when they thought about the event on a five-point scale (ranging from 'no reliving' to 'as if it were happening now'). They were told that they should indicate how much they "experienced the event again", "felt the same emotions again", and "traveled back in time" when they thought about the event (Brewer, 1996). The other half of the participants rated how vivid their memory of the event was on a five-point scale (ranging from 'not vivid' to 'very vivid'). They were told that they should indicate if they could retrieve visual images of the event and how easy it was to retrieve these images. The low-to-high direction of these scales was counterbalanced with half the participants getting high to low. We specifically opted for a procedure in which participants would rate the events after they had recalled them, so the participants would not intentionally search for events that they could relive strongly or which were particularly vivid.

At the end of the study, the subjects were thanked for their participation and were explained the background of the experiment. They were also given the opportunity to ask questions or give comments about the study and to invite relatives, friends, and colleagues, by sending them standardized e-mails.

\section{Results}

Given the considerations associated with Internet testing (e.g., Gosling et al., 2004; Reips, 2000, 2002; Schmidt,
1997), several measures were undertaken to ensure quality control. In order to reduce the likelihood of missing data, the task was structured such that participants had to complete each question before proceeding. The analyses were restricted to questionnaires that were completed. Participants could take the questionnaire as often as they wanted, but only the results of their first participation were analyzed. Thirty-six questionnaires were dropped from the analyses, because they were the second or third participation. Furthermore, the results of 8 questionnaires that had a coefficient of variation (i.e., the standard deviation divided by the mean) lower than 0.1 on the ages of the events were omitted. Finally, the results of 51 questionnaires were not included in the analyses, since the participants had taken longer than 60 minutes to complete them.

The questionnaires of the previously mentioned 2341 participants had met all criteria. These participants took on average $23 \min 45 \mathrm{~s}$ to complete the study. Completion time was unrelated to the reliving and vividness ratings $(p=.33$ and $p=.86)$.

\section{The reminiscence bump}

We will first examine whether there is a reminiscence bump present in the temporal distribution of the autobiographical memories, before the effects of reliving and vividness are investigated. A reminiscence bump in adolescence was readily observed in the lifetime distributions. The participants, who were between 16 and 75 years of age, were divided into 12 five-year age groups (see Table 1). One observed lifetime distribution (i.e., the proportion of personal events per five years) was calculated for each of these 12 age groups as shown in Fig. 1. To make the figure clearer, the 12 distributions are divided over three panels. The distributions of the age groups 26-30 and older all show a peak in the period in which the participants were between 6 and 10 years old. These peaks were not observed in the distributions of the two youngest age groups 16-20 and $21-25$, possibly because they were obscured by the increased recall of recent events (Janssen et al., 2005).

The reminiscence bump becomes more pronounced when one removes the increased recall of recent events from the observed lifetime distributions. In Fig. 2, the proportion of recalled events of the 15 most recent years is given as a function of the age of the event, with the proportion of events in each year plotted at the middle of that year. Participants recalled many events from the most recent year $(24.0 \%)$ and fewer events from previous years $(9.1 \%, 4.2 \%, 2.9 \%$ and $2.3 \%)$. For every doubling of the retention interval, the level of recall was reduced by about half. The recent events were fitted with a power function (Rubin \& Wenzel, 1996) with constant .12 and exponent $-.96,\left(R^{2}=.99\right)$. 

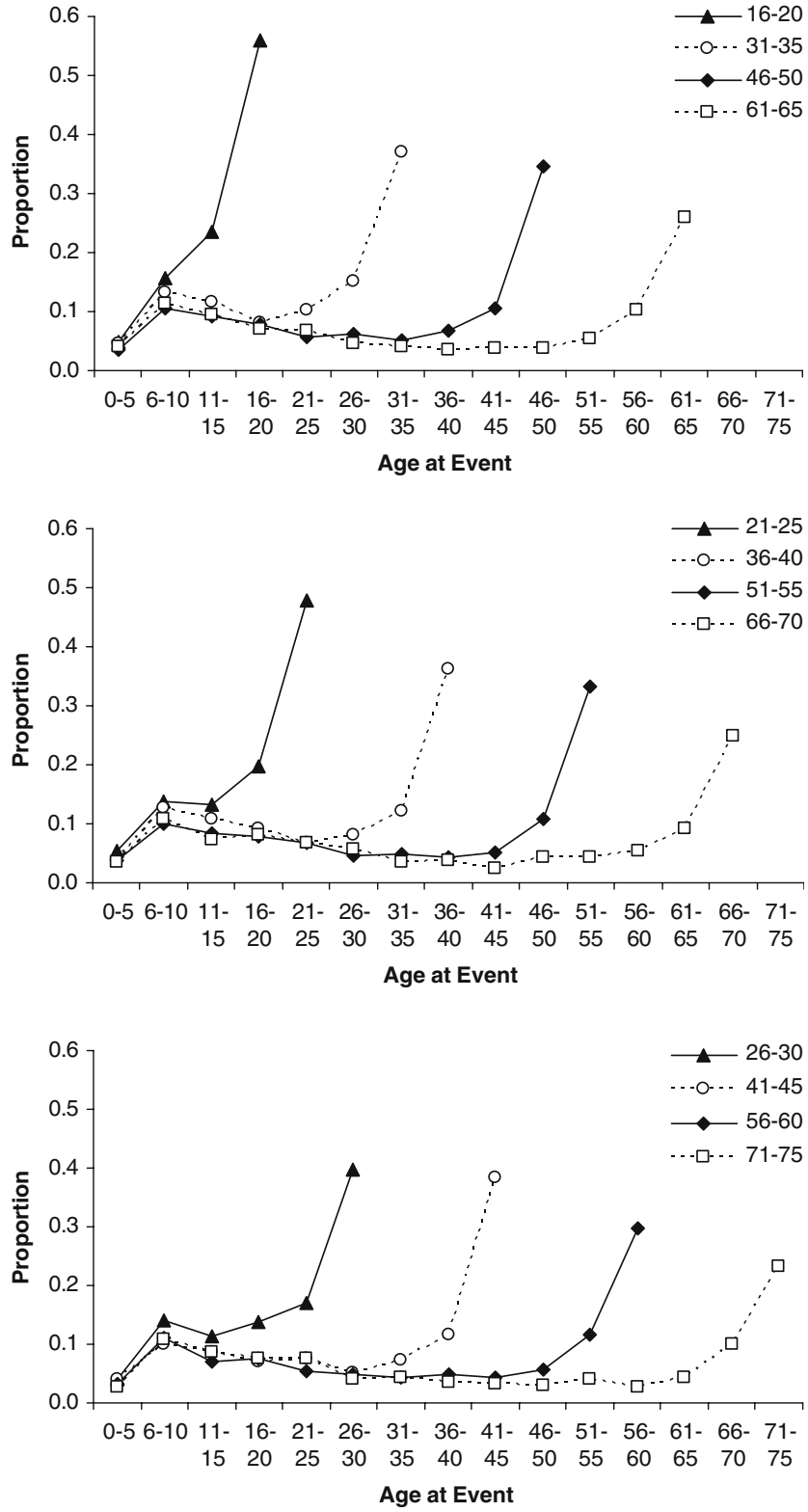

Fig. 1 The observed lifetime distributions per age group

The events from the 15 most recent years (Fig. 2) were removed from each plot in Fig. 1 before the individual plots from Fig. 1 were averaged to form Fig. 3. Only years for which there were data were averaged. Thus, all participants contributed to the early years, but fewer participants contributed to the later years. These individual year values were then adjusted to produce the five-year and ten-year age bins. The proportions in this figure are displayed per year (hollow circles), per five years (solid squares) or per ten years (solid triangles). To keep the proportion shown in the figure comparable, we display the proportion per year for all three plots. The actual proportion of the total number of memories is therefore five times of what is shown for the five-year age bins and ten times the proportion of what is

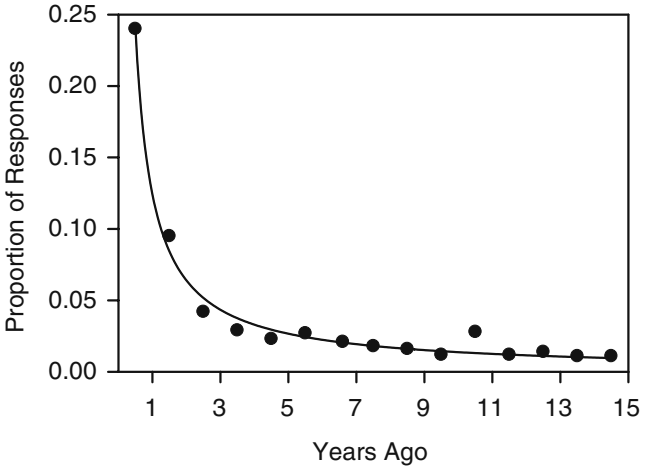

Fig. 2 Proportion of recalled events from the 15 most recent years as a function of age of the event averaged over the twelve age groups

shown for the ten-year age bins. Figure 3 shows that when one uses age bins of different sizes, the peak of the reminiscence bump can change, even when the same data are being used. When the results are given in one-year or five-year age bins, the peak of the bump is located between the ages of 6 and 10, but when ten-year age bins are used, the peak shifts to the second decade (11-20 years).

\section{Reliving}

Half of the participants was asked to indicate how much they relived the personal events when they thought about the events on a five-point scale that ranged from 'no reliving' (1) to 'as if it were happening now' (5). In general, participants reported moderate reliving when they thought about the personal events $(M=3.30, S D=1.29)$.

The reliving ratings will be examined in terms of (1) the age of the participant at the event, (2) the age of the event and (3) the age of the participant at the test. If a participant was 40 years old when he or she took the test (age of the participant) and he or she recalled an event that had happened 30 years ago (age of the event), then this participant was 10 years old when the event occurred (age

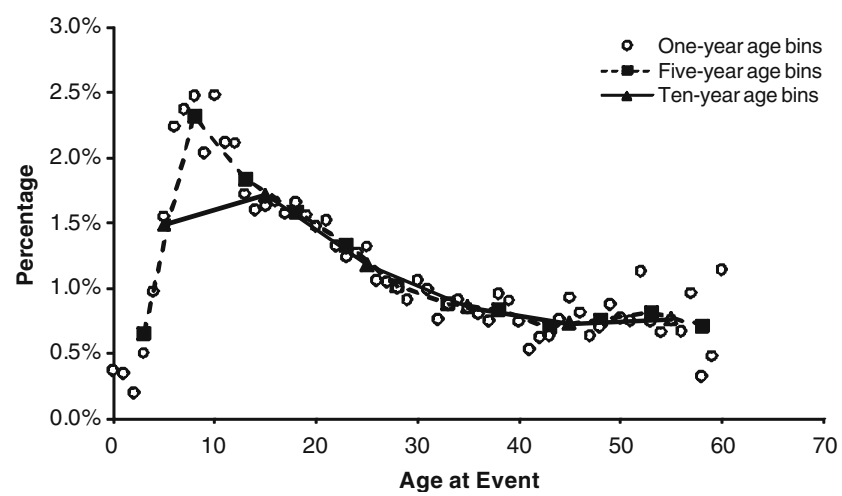

Fig. 3 Proportion of recalled events without the 15 most recent years as a function of age at the event averaged over the twelve age groups. Events are grouped per year (hollow circles), per five years (solid squares) or per ten years (solid triangles) 
at the event). These three variables are not independent. The age of the event plus the age at the event equals the age of the participant. The correlations between the age of the event and the age at the event $(r=-.70, p<.001)$, the age of the participant and the age of the event $(r=.40, p<.001)$ and between the age of the participant and the age at the event $(r=.38, p<.001)$ are therefore strong.

There were small effects of age at the event, age of the event, and age of the participant on reliving. Assuming that the memories are independent units, these three correlations are: $.08,-.03$, and .07 , respectively (all $p \mathrm{~s}<.001$ ). For the age of the participant, one can average all the memories of each participant and report a correlation in which the participant is unit of analysis. This correlation is: .11 $(p<.001)$. For the two other measures, separate correlations can be reported for different age groups to ensure that the confounding with age group does not cause the effect. For the age at event, if we divide the participants into the three age groups as shown in Table 1, the correlations for the young, middle-aged, and older adults are: $.08, .04$, and .09 , respectively (all $p \mathrm{~s}<.001$ ). For the age of event, the correlations for the young, middle-aged, and older adults are: $-.07,-.02$, and -.07 , respectively (all $p$ s $<.001$ ).

In order to present the underlying data for these analyses in as direct a way as possible, the average amount of reliving for events that occurred more than five years ago as a function of the age at the event has been given in Fig. 4 . The striped bars represent memories of young adults, the white bars represent memories of middle-aged adults, and the black bars represent memories of older adults. As can be seen, there are small effects on reliving that are consistent with the reported analyses.

To examine the effect of the age at the event more closely, events that had taken place in the period in which the participants were between 6 and 20 years old were compared to personal events from other lifetime periods. Events from the reminiscence bump $(M=3.20, S D=1.22)$ were relived less than events that had occurred before the

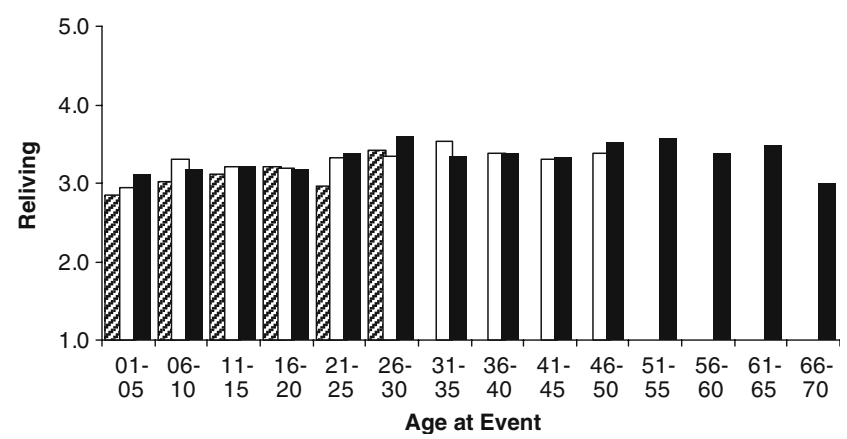

Fig. 4 The average reliving of memories about personal events that occurred more than five years ago as a function of the age of the participant at the time of the event for young adults (striped bars), middle-aged adults (white bars) and older adults (black bars) age of 6 or after the age of $20(M=3.34, S D=1.33)$, $t(11538)=5.77, p<.001$. Because most participants recalled at least one event from within and outside of the bump period, an analysis was also possible using participants as the unit of analysis. For each participant, one average for the reliving of the events that had occurred during the reminiscence bump period and another average of the events that had not occurred in that period were calculated. Events from the reminiscence bump $(M=3.20, S D=0.95)$ were relived less than events that had occurred before the age of 6 or after the age of $20(M=3.35, S D=0.87), t(949)=$ $5.11, p<.001$. In this last analysis, participants were excluded if they did not recall any events from the reminiscence bump period $(N=148)$ or did not recall any events from the period before or after the reminiscence bump $(N=33)$. To ensure that these results were not unduly affected by memories that had occurred in early childhood, the analyses were repeated comparing the reliving ratings of events that occurred during the reminiscence bump period to the ratings of events that had occurred after this period. For the by memory and by participant analyses, the postreminiscence bump memories had mean reliving ratings of $3.37(S D=1.32, t(10950)=6.58, p<.001)$ and $3.40(S D=$ $0.88, t(908)=6.53, p<.001)$, respectively.

\section{Vividness}

The half of the participants who did not rate reliving was asked to indicate how vivid their memories of the events were on a five-point scale that ranged from 'not vivid' (1) to 'very vivid' (5). The participants remembered their personal events on average vividly. The average vividness of their memories was $3.78(S D=1.23)$.

There were small effects of age at the event, age of the event, and age of the participant on vividness. Assuming that the memories are independent units, these three correlations are: $.19,-.14$, and .06 , respectively (all $p \mathrm{~s}<.001)$. For the age of the participant, one can average all the memories of each participant and report a correlation in which the participant is unit of analysis. This correlation is: $.10(p<.001)$. For the two other measures, separate correlations can be reported for different age groups to ensure that the confounding with age group does not cause the effect. For the age at the event, if we divide the participants into the three age groups as shown in Table 1, the correlations for the young, middle-aged, and older adults are, respectively, .19, .23, and .15 (all $p \mathrm{~s}<.001$ ). For the age of the event, the correlations for the young, middleaged, and older adults are, respectively, $-.20,-.22$, and -.15 (all $p$ s $<.001$ ).

The average vividness of memories about personal events that occurred more than five years ago as a function of the age of the participant at the time of the event is given 
in Fig. 5. Memories of young adults are represented by the striped bars, memories of middle-aged adults are represented by the white bars, and memories of older adults are represented by the black bars.

Personal events that had taken place in the period in which the participants were between 6 and 20 years old $(M=3.54, S D=1.18)$ were remembered less vividly than events from other lifetime periods $(M=3.90, S D=1.23)$, $t(11686)=15.13, p<.001$. When for each participant one average for the vividness of the events that had occurred during the reminiscence bump period and another average of the events that had not occurred in that period were calculated, events that had happened when the participants were younger than 6 years or older than 20 years $(M=3.84$, $S D=0.85$ ) were on average remembered more vividly than the events that had taken place when the participants were between 6 and 20 years old $(M=3.48, S D=0.97), t(973)=$ $12.14, p<.001$. Participants, who did not recall any events from the reminiscence bump period $(N=171)$ or who did not recall any events from the period before or after the reminiscence bump $(N=37)$, were excluded from this last analysis. To ensure that these results were not unduly affected by memories about events that had occurred in early childhood, the analyses were repeated comparing reminiscence bump memories to memories after the bump. For the by memory and by participant analyses, the postreminiscence bump memories had mean vividness ratings of $3.94(S D=1.21, t(11121)=16.74, p<.001)$ and 3.92 , $(S D=0.85, t(938)=14.38, p<.001)$, respectively.

\section{Discussion}

Few effects in the autobiographical memory literature are as well-established as the reminiscence bump, but none of the proposed mechanisms has successfully explained the reminiscence bump in the distribution of word-cued memories. In the present study, we investigated whether

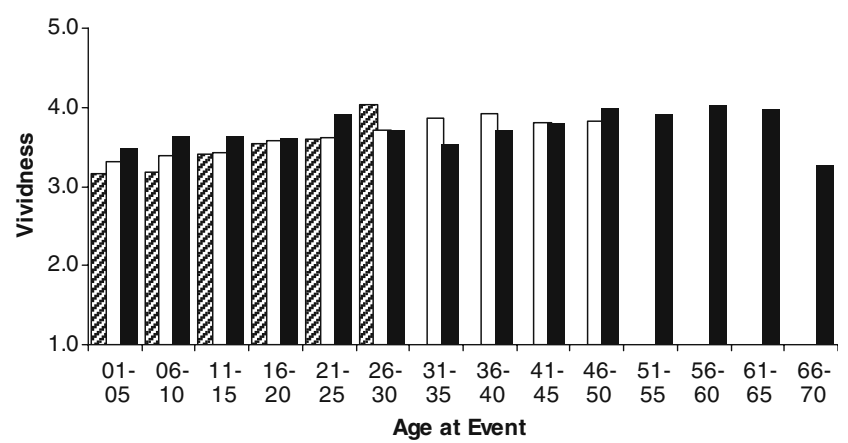

Fig. 5 The average vividness of memories about personal events that occurred more than five years ago as a function of the age of the participant at the time of the event for young adults (striped bars), middle-aged adults (white bars) and older adults (black bars) memories about personal events that had occurred during the reminiscence bump were associated with higher levels of reliving and vividness compared to memories about events from other lifetime periods. Participants recalled more personal events from the period in which they were between 6 and 20 years old. The reminiscence bump peaked in the period in which the participants were between 6 and 10 years old, which is earlier than most studies that used cue words have found, but there are several studies which have found such an early peak (e.g., Cohen \& Faulkner, 1988; Conway, Wang, Hanyu, \& Haque, 2005; Jansari \& Parkin, 1996; Rybash \& Monaghan, 1999). This could be caused by differences in instructions. For instance, when Rubin and Schulkind (1997) requested memories and used an example of a childhood event, their plot resembled that of Fig. 3. However, when they requested events and used a recent event as an example, their plot peaked a decade later. When the current results were presented in age bins of ten years, the peak of the reminiscence bump was located in the second decade of participants' lives, indicating that the size of the bins used can also have an effect on the location of the peak.

The events from the reminiscence bump were on average not given higher ratings of reliving and vividness. These results are in correspondence with the results of Rybash and Monaghan (1999) who had previously found that the temporal distributions of personal events that had been given remember or know judgments were identical. Thus, as with measures of novelty, emotionality and importance (e.g., Conway \& Haque, 1999; Janssen \& Murre, 2008; Maki \& Naka, 2006; Rubin \& Schulkind, 1997), vividness and reliving are not rated higher in the reminiscence bump. The simplest explanation for this is that all these measures are related to long lasting, highly available memories; such memories are recalled frequently to cue words. Recent memories follow the same principle, but because they have suffered less forgetting, they are recalled with even more vividness and reliving. The greater number of such long lasting, highly available memories in the reminiscence bump could be caused by the nature of encoding in that period or by the nature of the events from that period or by the role of these events in the life story or identity formation, which could lead to better encoding and to greater rehearsal.

The amount of reliving and the level of vividness were affected by the age of the event and the age of the participant at the test. First, recent events were relived more and remembered more vividly than remote events. These results are in line with the view that memories of recent events tend to be episodic, whereas memories of remote events are usually more semantic (Cermak, 1984). They are also consistent with normal forgetting of the sensory and emotional aspects of autobiographical memories that would 
support the judgments of reliving and vividness. Second, older participants reported higher ratings of reliving and vividness than younger participants. This effect was not caused by the age of the events, since older participants also gave higher ratings for recent events. The present study is not the first one to find this surprising result. Rubin and Schulkind (1997) and Rubin and Berntsen (2009) found that older adults gave higher ratings of vividness than young adults. These findings on the phenomenological ratings of memories contrast with measures of amount recalled where older adults tend to perform worse than young adults on episodic memory tests, while they often perform at similar levels on semantic memory tests (e.g., Craik \& Jennings, 1992; Mäntylä, 1993; Park, 2000). This may represent a real difference between the amount of recollection, a general trend for older adults to rate many properties as higher, or a recalibration of the scales over the life span. The personal events recalled in this study were probably better recollected than most autobiographical memories, since they were highly accessible. The existing data do not provide an easy way to reconcile these different accounts.

Three temporal effects were examined in this study. Recent events were relived more and remembered more vividly than older events, older participants gave higher ratings of reliving and vividness than younger participants, but memories from the reminiscence bump did not elicit stronger feelings of reliving and were not remembered more vividly. The results suggest that personal events from middle childhood to early adulthood are not recalled differently than events from other lifetime periods, there are just more of them.

Open Access This article is distributed under the terms of the Creative Commons Attribution Noncommercial License which permits any noncommercial use, distribution, and reproduction in any medium, provided the original author(s) and source are credited.

\section{References}

Alvarez, R., \& Squire, L. R. (1994). Memory consolidation and the medial temporal lobe: A simple network model. Proceedings of National Academy of Sciences, 91, 7041-7045.

Berntsen, D., \& Rubin, D. C. (2002). Emotionally charged autobiographical memories across the life span: The recall of happy, sad, traumatic, and involuntary memories. Psychology and Aging, 17, 636-652. doi:10.1037//0882-7974.17.4.636.

Berntsen, D., \& Rubin, D. C. (2004). Cultural life scripts structure recall from autobiographical memory. Memory \& Cognition, 32, 427-442.

Bohn, A. (in press). Generational differences in cultural life scripts and life story memories of younger and older adults. Applied Cognitive Psychology. doi:10.1002/acp.1641.

Brewer, W. F. (1986). What is autobiographical memory? In D. C. Rubin (Ed.), Autobiographical memory (pp. 25-49). Cambridge: Cambridge University Press.
Brewer, W. F. (1996). What is recollective memory? In D. C. Rubin (Ed.), Remembering our past: Studies in autobiographical memory (pp. 19-66). Cambridge: Cambridge University Press.

Cerella, J., \& Hale, S. (1994). The rise and fall in informationprocessing rates over the life span. Acta Psychologica, 86, 109197.

Cermak, L. S. (1984). The episodic-semantic distinction in amnesia. In L. R. Squire \& N. Butters (Eds.), The neuropsychology of memory (pp. 55-62). New York: Guilford Press.

Cohen, G., \& Faulkner, D. (1988). Life span changes in autobiographical memory. In M. M. Gruneberg, P. E. Morris, \& R. N. Sykes (Eds.), Practical aspects of memory: Current research and issues: Vol. 1. Memory in everyday life (pp. 277-282). New York: Wiley.

Conway, M. A. (2005). Memory and the self. Journal of Memory and Language, 53, 594-628. doi:10.1016/j.jml.2005.08.005.

Conway, M. A., \& Haque, S. (1999). Overshadowing the reminiscence bump: Memories of a struggle for independence. Journal of Adult Development, 6, 35-44. doi:1068-0667/99/0100-0035.

Conway, M. A., \& Pleydell-Pearce, C. W. (2000). The construction of autobiographical memories in the self-memory system. Psychological Review, 107, 261-288. doi:10.1037//0033-295X.107.2.261.

Conway, M. A., Singer, J. A., \& Tagini, A. (2004). The self and autobiographical memory: Correspondence and coherence. Social Cognition, 22, 491-529.

Conway, M. A., Wang, Q., Hanyu, K., \& Haque, S. (2005). A crosscultural investigation of autobiographical memory: On the universality and cultural variation of the reminiscence bump. Journal of Cross-Cultural Psychology, 36, 739-749. doi:10.1177/0022022105280512.

Craik, F. I. M., \& Jennings, J. M. (1992). Human memory. In F. I. M. Craik \& T. A. Salthouse (Eds.), The handbook of aging and cognition (pp. 51-110). Hillsdale: Lawrence Erlbaum.

Crovitz, H. F., \& Schiffman, H. (1974). Frequency of episodic memories as a function of their age. Bulletin of the Psychonomic Society, 4, 517-518.

Daselaar, S. M., Rice, H. J., Greenberg, D. L., Cabeza, R., LaBar, K. S., \& Rubin, D. C. (2008). The spatiotemporal dynamics of autobiographical memory: Neural correlates of recall, emotional intensity and reliving. Cerebral Cortex, 18, 217-229. doi:10.1093/cercor/bhm048.

Dewhurst, S. A., \& Conway, M. A. (1994). Pictures, images and recollective experience. Journal of Experimental Psychology. Learning, Memory, and Cognition, 20, 1088-1098.

Fitzgerald, J. M. (1988). Vivid memories and the reminiscence phenomenon: The role of a self narrative. Human Development, $31,261-273$.

Fitzgerald, J. M. (1996). The distribution of self-narrative memories in younger and older adults: Elaborating the selfnarrative hypothesis. Aging, Neuropsychology, and Cognition, 3, 229-236.

Galton, F. (1879). Psychometric experiments. Brain, 2, 149-162.

Gardiner, J. M. (1988). Functional aspects of recollective experience. Memory \& Cognition, 16, 309-313.

Gardiner, J. M., \& Java, R. I. (1990). Recollective experience in word and nonword recognition. Memory \& Cognition, 18, 23-30.

Gardiner, J. M., \& Java, R. I. (1991). Forgetting in recognition memory with and without recollective experience. Memory \& Cognition, 19, 617-623.

Gardiner, J. M., \& Parkin, A. J. (1990). Attention and recollective experience in recognition memory. Memory \& Cognition, 18, $579-583$.

Gosling, S. D., Vazire, S., Srivastava, S., \& John, O. P. (2004). Should we trust web-based studies? A comparative analysis of six preconceptions about internet questionnaires. The American Psychologist, 59, 93-104. doi:10.1037/0003-066X.59.2.93. 
Holbrook, M. B., \& Schindler, R. M. (1989). Some exploratory findings on the development of musical tastes. Journal of Consumer Research, 16, 119-124.

Holbrook, M. B., \& Schindler, R. M. (1996). Market segmentation based on age and attitude toward the past: Concepts, methods, and findings concerning nostalgic influences on customer tastes. Journal of Business Research, 37, 27-39.

Holmes, A., \& Conway, M. A. (1999). Generation identity and the reminiscence bump: Memory for public and private events. Journal of Adult Development, 6, 21-34. doi:1068-0067/99/0100-0021.

Howes, J. L., \& Katz, A. N. (1992). Remote memory: Recalling autobiographical and public events from across the lifespan. Canadian Journal of Psychology, 46, 92-116.

Jansari, A., \& Parkin, A. J. (1996). Things that go bump in your life: Explaining the reminiscence bump in autobiographical memory. Psychology and Aging, 11, 85-91.

Janssen, S. M. J., Chessa, A. G., \& Murre, J. M. J. (2005). The reminiscence bump in autobiographical memory: Effects of age, gender, education, and culture. Memory, 13, 658-668. doi: 10.1080/09658210444000322.

Janssen, S. M. J., Chessa, A. G., \& Murre, J. M. J. (2006). Memory for time: How people date events. Memory \& Cognition, 34, 137-148.

Janssen, S. M. J., Chessa, A. G., \& Murre, J. M. J. (2007). Temporal distribution of favourite books, movies and records: Differential encoding and resampling. Memory, 15, 755-767. doi:10.1080/ 09658210701539646.

Janssen, S. M. J., \& Murre, J. M. J. (2008). Reminiscence bump in autobiographical memory: Unexplained by novelty, emotionality, valence and importance. The Quarterly Journal of Experimental Psychology, 61, 1847-1860. doi:10.1080/17470210701774242.

Janssen, S. M. J., Murre, J. M. J., \& Meeter, M. (2008). Reminiscence bump in memory for public events. European Journal of Cognitive Psychology, 20, 738-764. doi:10.1080/09541440701554409.

Janssen, S. M. J., \& Rubin, D. C. (in press). Age effects in cultural life scripts. Applied Cognitive Psychology. doi:10.1002/acp.1690.

Kristo, G., Janssen, S. M. J., \& Murre, J. M. J. (2009). Retention of autobiographical memories: An Internet-based diary study. Memory, 17, 816-829. doi:10.1080/09658210903143841.

Larsen, S. F. (1996). Memorable books: Recall of reading and its personal context. In R. Kreuz \& M. S. MacNealy (Eds.), Empirical approaches to literature and aesthetics (pp. 585-599). Norwood: Ablex.

Levine, B., Svoboda, E., Hay, J. F., Winocur, G., \& Moscovitch, M. (2002). Aging and autobiographical memory: Dissociating episodic from semantic retrieval. Psychology and Aging, 17, 677-689. doi:10.1037//0882-7974.17.4.677.

Li, S.-C., Lindenberger, U., Hommel, B., Ascherleben, G., Prinz, W., \& Baltes, P. B. (2004). Transformations in the couplings among intellectual abilities and constituent cognitive processes across the life span. Psychological Science, 15, 155-163.

Maki, Y., \& Naka, M. (2006). Reminiscence bump and contents of autobiographical memory in Japanese elders. Japanese Journal of Psychology, 77, 333-341.

Mäntylä, T. (1993). Knowing but not remembering: Adult age differences in recollective experience. Memory \& Cognition, 21, 379-388.

Meeter, M., \& Murre, J. M. J. (2004). Consolidation of long-term memory: Evidence and alternatives. Psychological Bulletin, 130, 843-857. doi:10.1037/0033-2909.130.6.843.

Meeter, M., Murre, J. M. J., \& Janssen, S. M. J. (2005). Remembering the news: Modeling retention data from a study with 14,000 participants. Memory \& Cognition, 33, 793-810.

Meeter, M., Ochtman, D. J. C., Janssen, S. M. J., \& Murre, J. M. J. (2010). Of sports and politics: Predicting category-specific retention of news events from demographic variables. European Journal of Cognitive Psychology, 22, 117-129. doi:10.1080/09541440802708037.
Murre, J. M. J. (1996). TraceLink: A model of amnesia and consolidation of memory. Hippocampus, 6, 675-686.

Murre, J. M. J. (1997). Implicit and explicit memory in amnesia: Some explanations and predictions by the TraceLink model. Memory, 5, 213-232.

Paivio, A., Yuille, J. C., \& Madigan, S. A. (1968). Concreteness, imagery and meaningfulness value for 925 nouns. Journal of Experimental Psychology, Monograph Supplement, 76, 1-25.

Park, D. C. (2000). The basic mechanism accounting for age-related decline in cognitive function. In D. C. Park \& N. Schwarz (Eds.), Cognitive aging: A primer (pp. 3-21). Philadelphia: Psychology Press.

Pillemer, D. B. (2001). Momentous events and the life story. Review of General Psychology, 5, 123-134. doi:10.1037//1089-2680.5.2.123.

Piolino, P., Desgranges, B., Benali, K., \& Eustache, F. (2002). Episodic and semantic remote autobiographical memory in ageing. Memory, 10, 239-257. doi:10.1080/09658210143000353.

Piolino, P., Desgranges, B., Clarys, D., Guillery-Girard, B., Taconnat, L., Isingrini, M., et al. (2006). Autobiographical memory, autonoetic consciousness, and self- perspective in aging. Psychology and Aging, 21, 510-525. doi:10.1037/0882-7974.21.3.510.

Rajaram, S. (1993). Remembering and knowing: Two means of access to the personal past. Memory \& Cognition, 21, 89-102.

Rathbone, C. J., Moulin, C. J. A., \& Conway, M. A. (2008). Self-centered memories: The reminiscence bump and the self. Memory \& Cognition, 36, 1403-1414. doi:10.103758/MC.36.8.1403.

Reips, U.-D. (2000). The web experiment method: Advantages, disadvantages, and solutions. In M. H. Birnbaum (Ed.), Psychological experiments on the Internet (pp. 89-114). San Diego: Academic Press.

Reips, U.-D. (2002). Standards for internet-based experimenting. Experimental Psychology, 49, 243-256. doi:10/1027//1618-3169.49.4.243.

Robinson, J. A. (1976). Sampling autobiographical memory. Cognitive Psychology, 8, 578-595.

Robinson, J. A. (1986). Autobiographical memory: A historical prologue. In D. C. Rubin (Ed.), Autobiographical memory (pp. 19-24). Cambridge: Cambridge University Press.

Robinson, J. A. (1992). First experience memories: Context and functions in personal histories. In M. A. Conway, D. C. Rubin, H. Spinnler, \& W. A. Wagenaar (Eds.), Theoretical perspectives on autobiographical memory (pp. 223-236). Dordrecht: Kluwer Academic.

Rosenbaum, R. S., Winocur, G., \& Moscovitch, M. (2001). New views on old memories: Re- evaluating the role of the hippocampal complex. Behavioral Brain Research, 127, 183197.

Rubin, D. C., \& Berntsen, D. (2003). Life scripts help to maintain autobiographical memories of highly positive, but not highly negative, events. Memory \& Cognition, 31, 1-14.

Rubin, D. C., \& Berntsen, D. (2009). The frequency of voluntary and involuntary autobiographical memories across the lifespan. Memory \& Cognition, 37, 679-688. doi:10.3758/37.5.679.

Rubin, D. C., Berntsen, D., \& Hutson, M. (2009). The normative and the personal life: Individual differences in life scripts and life story events among USA and Danish undergraduates. Memory, 17, 54-68. doi:10.1080/09658210802541442.

Rubin, D. C., Rahhal, T. A., \& Poon, L. W. (1998). Things learned in early adulthood are remembered best. Memory \& Cognition, 26, $3-19$.

Rubin, D. C., Schrauf, R. W., \& Greenberg, D. L. (2003). Belief and recollection of autobiographical memories. Memory \& Cognition, 31, 887-901.

Rubin, D. C., \& Schulkind, M. D. (1997). Distribution of important and word-cued autobiographical memories in 20-, 35-, and 70year-old adults. Psychology and Aging, 12, 524-535. 
Rubin, D. C., \& Siegler, I. C. (2004). Facets of personality and the phenomenology of autobiographical memory. Applied Cognitive Psychology, 18, 913-930. doi:10.1002/acp.1038.

Rubin, D. C., \& Wenzel, A. E. (1996). One hundred years of forgetting: A quantitative description of retention. Psychological Review, 103, 734-760.

Rubin, D. C., Wetzler, S. E., \& Nebes, R. D. (1986). Autobiographical memory across the adult life span. In D. C. Rubin (Ed.), Autobiographical memory (pp. 202-221). Cambridge: Cambridge University Press.

Rybash, J. M. (1999). Aging and autobiographical memory: The long and bumpy road. Journal of Adult Development, 6, 1-10. doi:1068-0067/99/0100-0001.

Rybash, J. M., \& Monaghan, B. E. (1999). Episodic and semantic contributions to older adults' autobiographical recall. The Journal of General Psychology, 126, 85-96.

Salthouse, T. A. (2004). What and when of cognitive aging. Current Directions in Psychological Science, 13, 140-144.

Schmidt, W. C. (1997). World-wide web survey research: Benefits, potential problems and solutions. Behavior Research Methods, Instruments, \& Computers, 29, 274-279.

Schooler, L. J., Shiffrin, R. M., \& Raaijmakers, J. G. W. (2001). A Bayesian model for implicit effects in perceptual identification. Psychological Review, 108, 257-272. doi:10.1037//0033-295X.108.1.257.
Schulkind, M. D., Hennis, L. K., \& Rubin, D. C. (1999). Music, emotion, and autobiographical memory: They're playing your song. Memory \& Cognition, 27, 948-955.

Schuman, H., Belli, R. F., \& Bischoping, K. (1997). The generational basis of historical knowledge. In J. W. Pennebaker, D. Paez, \& B. Rimé (Eds.), Collective memory of political events (pp. 47-77). Mahwah: Lawrence Erlbaum.

Sehulster, J. R. (1996). In my era: Evidence for the perception of a special period of the past. Memory, 4, 145-158.

Smith, T. W. (1994). Generational differences in musical preferences. Popular Music and Society, 18, 43-59.

Squire, L. R., Knowlton, B., \& Musen, G. (1993). The structure and organization of memory. Annual Review of Psychology, 44, 453495.

St. Jacques, P. L., \& Levine, B. (2007). Ageing and autobiographical memory for emotional and neutral events. Memory, 15, 129-144. doi:10.1080/09658210601119762.

Thomsen, D. K., \& Berntsen, D. (2008). The cultural life script and life story chapters contribute to the reminiscence bump. Memory, 16, 420-435. doi:10.1080/09658210802010497.

Tulving, E. (1985). Memory and consciousness. Canadian Psychology, 26, 1-12.

Tulving, E. (2002). Episodic memory: From mind to brain. Annual Review of Psychology, 53, 1-25. doi:0084-6570/02/0201.0001. 